\title{
Platelets: Physiology and Biochemistry
}

\author{
Kerstin Jurk, Ph.D., ${ }^{1}$ and Beate E. Kehrel, Ph.D. ${ }^{1,2}$
}

\section{ABSTRACT}

Platelets are specialized blood cells that play central roles in physiologic and pathologic processes of hemostasis, inflammation, tumor metastasis, wound healing, and host defense. Activation of platelets is crucial for platelet function that includes a complex interplay of adhesion and signaling molecules. This article gives an overview of the activation processes involved in primary and secondary hemostasis, for example, platelet adhesion, platelet secretion, platelet aggregation, microvesicle formation, and clot retraction/stabilization. In addition, activated platelets are predominantly involved in cross talk to other blood and vascular cells. Stimulated "sticky" platelets enable recruitment of leukocytes at sites of vascular injury under high shear conditions. Platelet-derived microparticles as well as soluble adhesion molecules, sP-selectin and sCD40L, shed from the surface of activated platelets, are capable of activating, in turn, leukocytes and endothelial cells. This article focuses further on the new view of receptor-mediated thrombin generation of human platelets, necessary for the formation of a stable platelet-fibrin clot during secondary hemostasis. Finally, special emphasis is placed on important stimulatory and inhibitory signaling pathways that modulate platelet function.

KEYWORDS: Platelet activation, platelet adhesion, platelet aggregation, procoagulant activity, thrombin generation

Objectives: On completion of the article, the reader should be able to (1) recite some physiological functions of platelets in hemostasis and (2) describe the principle of the receptor-mediated model of thrombin generation on the platelet surface.

Accreditation: Tufts University School of Medicine (TUSM) is accredited by the Accreditation Council for Continuing Medical Education to provide continuing medical education for physicians.

Credit: TUSM designates this educational activity for a maximum of 1 Category 1 credit toward the AMA Physicians Recognition Award. Each physician should claim only those credits that he/she actually spent in the educational activity.

Although the platelet was initially viewed only as a bystander in haemostasis, it is now evident that the platelet is in fact a key mediator of thrombosis as well as inflammation.

$$
\text { D.L. Bhatt and E.J. Topol }{ }^{1}
$$

Platelets, the smallest of the human blood cells $(3.6 \times 0.7 \mu \mathrm{m})$, are central players in processes of hemo- stasis and thrombosis. In addition, platelets are specialized cells of the innate immune defense, modulators of the inflammatory response, and involved in wound healing as well as in hematogenic metastasis. They are released from megakaryocytes in the bone marrow as anucleated fragments into the circulation. When a vessel wall is damaged, platelets are recruited from the circulation to the unveiled subendothelial matrix

Reliability of Platelet Function Tests and Drug Monitoring; Editor in Chief, Eberhard F. Mammen, M.D.; Guest Editors, Walter-Michael Halbmayer, M.D., Götz Nowak, M.D., Ernst Wenzel, M.D. Seminars in Thrombosis and Hemostasis, volume 31, number 4, 2005. Address for correspondence and reprint requests: Prof. Dr. Beate E. Kehrel, Department of Anaesthesiology and Intensive Care, Experimental and Clinical Haemostasis, University-Hospital Münster, Mendelstr. 11, 48149 Münster, Germany. E-mail: kehrel@uni-muenster.de. ${ }^{1}$ Department of Anaesthesiology and Intensive Care, Experimental and Clinical Haemostasis, University-Hospital Münster, Münster, Germany; ${ }^{2}$ Professor. Copyright (C) 2005 by Thieme Medical Publishers, Inc., 333 Seventh Avenue, New York, NY 10001, USA. Tel: +1(212) 584-4662. 0094-6176, p;2005,31,04,381,392,ftx,en;sth01075x. 
Table 1 Agonists, Ligands, and Receptors Important for Platelet Function

\begin{tabular}{|c|c|c|}
\hline Platelet Function & Agonists, Ligands & Receptors \\
\hline \multirow[t]{8}{*}{ Initial and firm adhesion } & vWF & GPIb/V/IX \\
\hline & TSP1 & GPIb/V/IX, CD36 \\
\hline & Collagen & $\alpha_{2} \beta_{1}$, GPVI, CD36 \\
\hline & Fibrinogen & $\alpha_{\| b} \beta_{3}$ \\
\hline & Fibronectin & $\alpha_{5} \beta_{1}{ }^{73}$ \\
\hline & Vitronectin & $\alpha_{\mathrm{v}} \beta_{3}{ }^{77}$ \\
\hline & Laminin & $\alpha_{6} \beta_{1}{ }^{74}$ \\
\hline & High shear stress & $\mathrm{GPIb} / \mathrm{V} / \mathrm{IX}$ \\
\hline \multirow[t]{10}{*}{ Activation and amplification } & Thrombin & PAR1, PAR4, GPIb/V/IX \\
\hline & ADP & $P 2 Y_{1}, P 2 Y_{12}$ \\
\hline & $\mathrm{TxA}_{2}$ & $\mathrm{TP} \alpha, \mathrm{TP} \beta$ \\
\hline & Epinephrine & $\alpha_{2 A}$ \\
\hline & Serotonin & 5-HT2A \\
\hline & MMP-2, MMP-1 ${ }^{75,76}$ & $?$ \\
\hline & Immune complexes & Fcylla \\
\hline & Complement factors & C1q, C3a, C5a receptors \\
\hline & Plasmin & $?$ \\
\hline & Streptokinase & $?$ \\
\hline \multirow[t]{7}{*}{ Aggregation/amplification and stabilization } & Fibrin & Activated $\alpha_{\| b} \beta_{3}$ \\
\hline & vWF & Activated $\alpha_{\| \mathrm{lb}} \beta_{3}, \mathrm{GPIb} / \mathrm{V} / \mathrm{IX}$ \\
\hline & TSP-1 ${ }^{77}$ & Activated $\alpha_{\| b} \beta_{3}$, CD36,IAP \\
\hline & Fibronectin & Activated $\alpha_{\| b} \beta_{3}$ \\
\hline & sCD40L & Activated $\alpha_{\| b} \beta_{3}$ \\
\hline & Gas6 & $\left.A x\right|^{78,79}$ \\
\hline & SDF-1, TARC, MDC & $\mathrm{CXCR} 4, \mathrm{CCR} 4^{80-82}$ \\
\hline
\end{tabular}

$\checkmark W F$, von Willebrand factor; TSP1, thrombospondin-1; ADP, adenosine diphosphate; $\operatorname{TxA}_{2}$, thromboxane $A_{2}$; MMP, matrix metalloproteinase; IAP, integrin associated protein; SDF, stromal cell-derived factor; TARC, thymus and activation-regulated chemokine; MDC, macrophage-derived chemokine.

forming a hemostatic plug to close the leak in the vessel wall. On the other hand, platelets form a thrombus at sites of ruptured atherosclerotic plaques, and in this way trigger heart attacks and strokes. The immobilization of platelets at sites of vascular injury requires specific platelet-vessel wall- (adhesion) and platelet-plateletinteractions (aggregation). The major agonists and adhesion molecules/receptors that mediate these interactions are summarized in Table 1.

\section{MECHANISMS OF PLATELET ACTIVATION}

The adhesion of platelets to the subendothelial matrix is the initial step in primary hemostasis. Platelets interact with extracellular matrix proteins via specific adhesive glycoproteins (GP). Binding of biochemical agonists to their receptors, receptor cross-linking, or changes in the plasma membrane induce a complex cascade of signals, transduced from the membrane into the cytoplasm, which results in platelet activation (outside-in signaling). ${ }^{2}$ In contrast to resting platelets, which are discoid with homogeneously distributed granules (Fig. 1A), activated platelets show a change in the assembly of cytoskeleton proteins resulting in a shape change with extensive formation of pseudopodia originating from the plasma membrane. ${ }^{3}$ Further, the granules centralize and fuse with the plasma membrane via exocytosis with secretion of the granule content (Fig. 1B). Some secretion products, such as adenosine diphosphate (ADP) and serotonin, potentiate the stimulation of more platelets, which are attracted to the damaged vessel wall. The activation of platelets is associated with the binding of fibrinogen to its major receptor GPIIb/IIIa $\left(\alpha_{\mathrm{IIb}} \beta_{3^{-}}\right.$ integrin), which is essential for platelet bridging and subsequent aggregation. During secondary hemostasis, the amplification of platelet stimulation leads to procoagulant activity, thrombin generation, and formation of a stable platelet-fibrin plug with subsequent clot retraction.

\section{Platelet Adhesion}

In certain conditions of flow, platelets have to slow down to stop at sites of vascular damage. The high molecular weight (1-10 $\mathrm{MDa})$ multimeric plasma protein von 
A
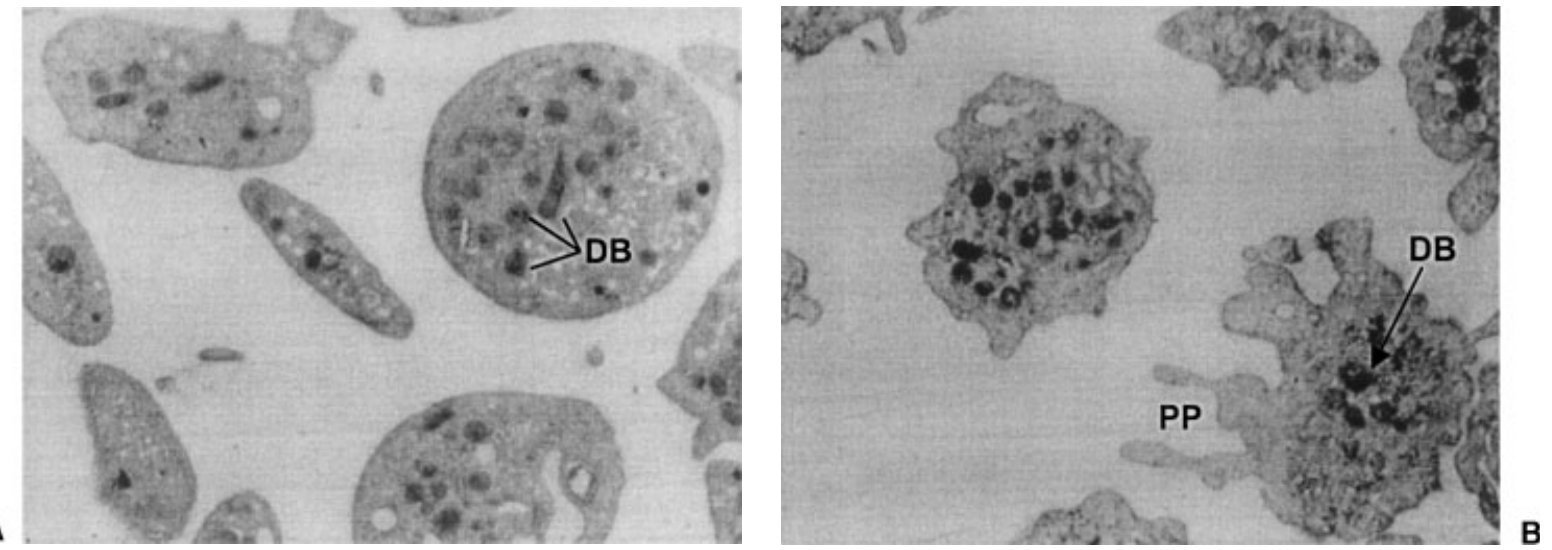

Figure 1 Morphology of human platelets. (A) Thin section of discoid resting platelets with evenly distributed granules. (B) Thin section of stimulated platelets, showing formation of pseudopodia and centralization of granules. DB, dense body; PP, pseudopodium. Magnification $\times 21,000$.

Willebrand factor (vWF) associates with the major matrix protein collagen on the surface of the subendothelium and serves as a substrate for platelet adhesion, predominantly under high shear. The multiple binding sites of vWF multimers enables first contacts to the $\mathrm{GPIb} / \mathrm{V} / \mathrm{IX}$ complex on platelets leading to formation of firm bonds and platelet capture. In contrast to vWF monomers, only dimers and multimers are able to crosslink and to activate the GPIb/V/IX complex. Conformational changes in the GPIb/V/IX or vWF molecule are thought to modulate these interactions. Under physiological conditions it is supposed that binding of $\mathrm{vWF}$ to collagen enables binding to GPIb/V/IX. ${ }^{4}$ Even point mutations in the vWF or GPIb induced spontaneous ligand binding. The antibiotic ristocetin or the snake venom ingredient botrocetin are used to induce vWF-GPIb/V/IX interaction in vitro. The modular glycoprotein thrombospondin-1 (TSP1), which is also integrated in the subendothelial matrix, has been identified to serve as an alternative adhesion substrate to vWF via GPIb under high shear conditions. ${ }^{5}$ In addition to PSGL1, the GPIb/V/XI complex enables rolling of activated platelets on the endothelium through endothelial P-selectin. ${ }^{6,7}$

Under static or low shear conditions, platelets adhere predominantly to collagen of the subendothelium. Collagen binds initially to GPIa/IIa, cross-links many of these integrin molecules, and in this way activates platelets. ${ }^{8}$ Patients who lack platelet GPIa/ IIa have bleeding problems. ${ }^{9}$ Other collagen receptors, such as CD36 and GPVI, play important roles in collagen-induced signaling. ${ }^{10,11}$ GPVI, the major signaling receptor, is a member of the immunoglobulin superfamily and is linked to the $\mathrm{Fc}$ receptor $\gamma$ chain. Its signaling pathway is similar to lymphocyte signaling. ${ }^{12}$ Stimulation of platelets as a result of adhesion leads to spreading, activation of GPIIb/IIa, enabling binding of soluble fibrinogen, and granule secretion (Fig. 2).

\section{Platelet Secretion}

Activated platelets release several granule components which modulate functions of interacting platelets and blood and vascular cells. Several secretion products of immobilized platelets stimulate additional circulating platelets which are recruited to form aggregates. The dense bodies of platelets contain important secondary agonists like ADP or serotonin. About $50 \%$ of platelet ADP is stored in the dense bodies (storage pool), which is released after platelet activation but cannot be refilled. In contrast, the metabolic pool of adenine nucleotides, localized in the cytoplasm but not connected to the dense bodies, is able to synthesize new ADP but cannot be released. ${ }^{13} \mathrm{ADP}$ is predicted to be the prominent amplifier of initial platelet activation. ${ }^{14}$ There are two important ADP receptors on the platelet surface. The $\mathrm{P}_{2} \mathrm{Y}_{1}$-receptor mediates mobilization of $\mathrm{Ca}^{2+}$ and shape change and transient aggregation. ${ }^{15}$ The $\mathrm{P}_{2} \mathrm{Y}_{12}$-receptor is believed to potentiate platelet secretion and to be involved in sustained irreversible aggregation. ${ }^{16}$ Enzymatic conversion of released ADP to inactive adenosine monophosphate (AMP) by endothelial ecto-ADPase/ CD39 limits platelet activation by ADP. ${ }^{17} \mathrm{~A}$ lack of the second aggregation wave after collagen stimulation characterizes disorders in ADP-mediated platelet activation.

Serotonin (5-hydroxytryptamine, 5-HT), a wellknown strong vasoconstrictor, binds to the Gq-coupled 5HT2A-receptor and amplifies together with ADP the platelet response. In addition, serotonin may play a procoagulant role in augmenting the retention of procoagulant proteins like fibrinogen and thrombospondin (TSP) on the platelet surface. ${ }^{18}$ The dense tubular system contains a $\mathrm{Ca}^{2+}$ pool which is mobilized during platelet activation. $\mathrm{Ca}^{2+}$ fluxes are central triggers in platelet activation, platelet attraction, and platelet aggregation. ${ }^{19}$ The $\alpha$-granules contain large adhesive proteins (vWF, TSP1, vitronectin, fibronectin), mitogenic factors (PDGF, VEGF, TGF $\beta$ ), coagulation 

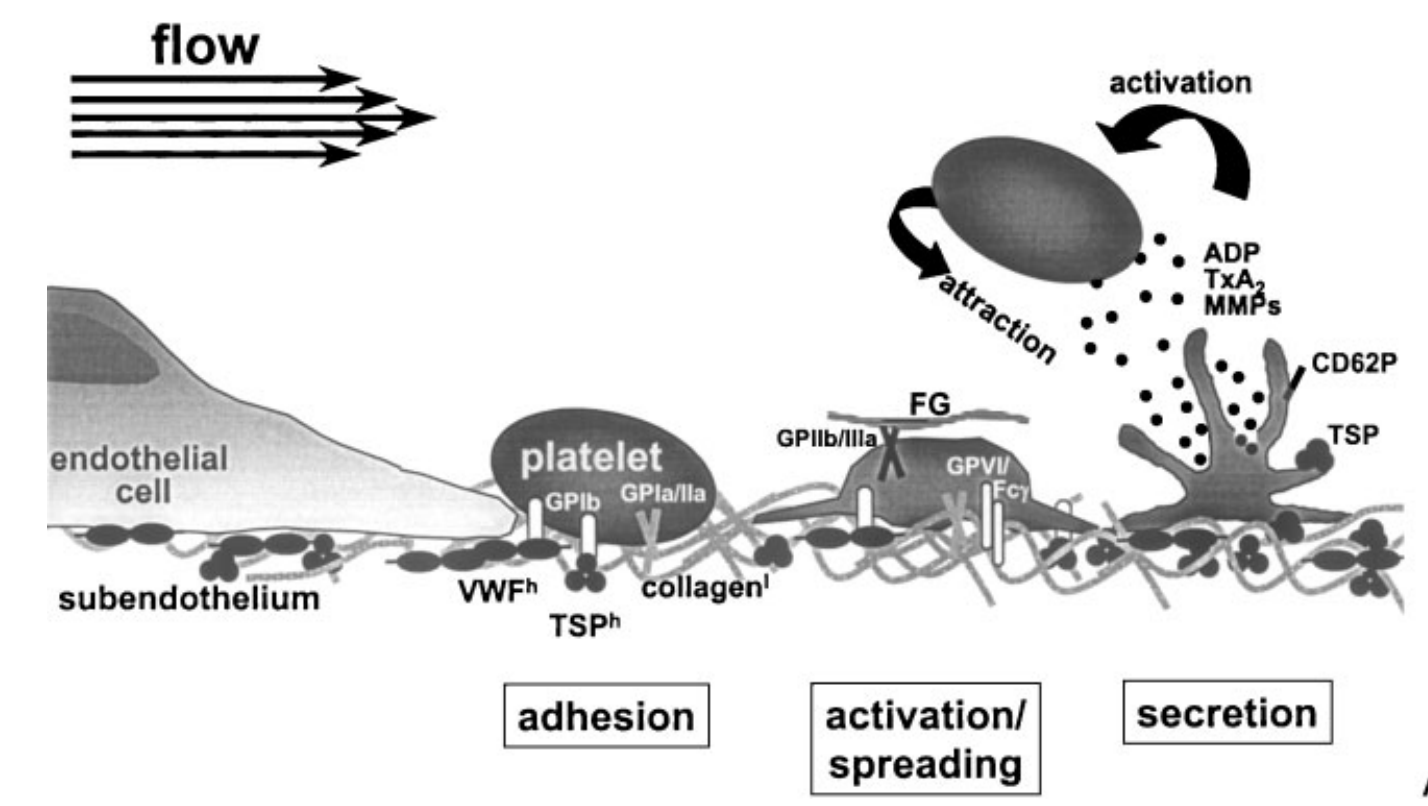

B
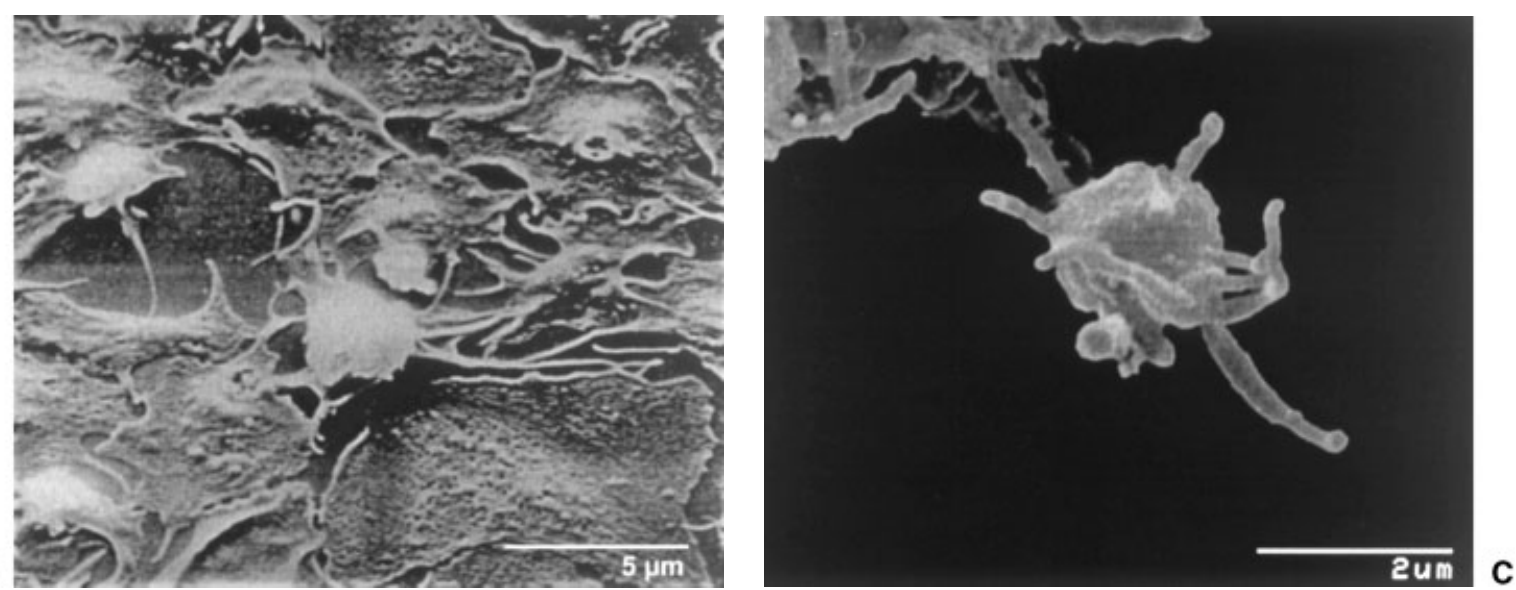

Figure 2 Primary hemostasis. (A) Platelets recruited from the circulation to the subendothelium of a damaged vessel wall adhere to VWF and TSP via GPIb/V/IX under high shear conditions (h). Collagen serves as adhesive substrate for platelets (via GPla/lla and GPVI/ $\mathrm{F}(\gamma)$ under low shear conditions (1). Receptor clustering through multiple binding sites of matrix proteins induce activation of GPIIb/IIla with subsequent binding of fibrinogen (FG) and platelet spreading. Activated platelets secrete several adhesive proteins, including TSP, which binds back to the platelet surface. Secreted secondary agonists (ADP, TxA 2 and MMPs) amplify activation and attraction of additional circulating platelets. (B) REM-preparation of human platelets adhered and spread on immobilized collagen. (C) Scanning electron microscope preparation of a thrombin-stimulated human platelet with marked pseudopodia. vWF, von Willebrand factor; TSP, thrombospondin, ADP, adenosine diphosphate; $\operatorname{TxA}_{2}$, thromboxane $\mathrm{A}_{2} ; \mathrm{MMPs}$, matrix metalloproteinases.

factors (factors V, VII, XI, XIII), and protease inhibitors (protein C, PAI-1, TFPI), which are released immediately after platelet activation. Some of the $\alpha$-granule proteins are synthesized by megakaryocytes (TSP1, ${ }^{20}$ $\beta$-thromboglobulin, platelet factor 4); others are endocytosed from the plasma (immunoglobulins, fibrinogen, vitronectin). Various glycoproteins, for example, $\mathrm{P}$-selectin $(\mathrm{CD} 62 \mathrm{P})$, are exclusively localized on the $\alpha$-granule membrane of resting platelets. Upon secretion the membrane of the $\alpha$-granule membrane fuses with the plasma membrane and exposes CD62P on the platelet surface. P-selectin and other activation-dependent glycoproteins, including CD40L, mediate platelet binding to neutrophils and monocytes. ${ }^{21}$ Leukocytes are able to roll on platelets, which are immobilized on the subendothelium, in a P-selectin-dependent manner (Fig. 2). ${ }^{22}$

\section{Platelet Aggregation}

The aggregation of platelets is characterized by the accumulation of platelets into a hemostatic plug (Fig. 3). The central platelet receptor in this process is the GPIIb/IIIa ( $\alpha_{\mathrm{IIb}} \beta_{3}$-integrin) linking activated platelets through fibrinogen bridges. A resting platelet presents $\sim 40,000$ to $50,000 \mathrm{GPIIb} / \mathrm{III}$ a complexes on its surface. In its nonactive state this integrin cannot 

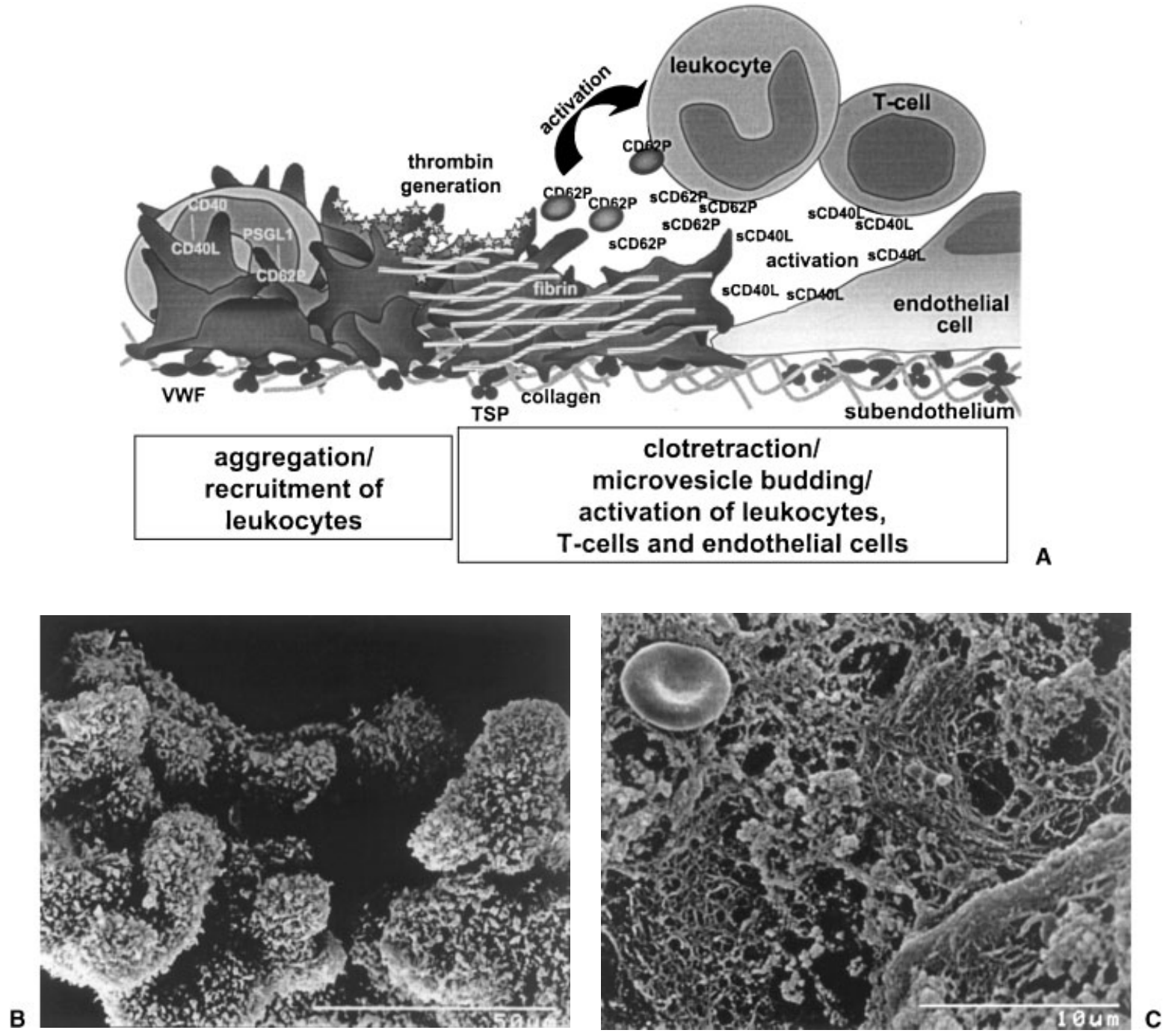

Figure 3 Aggregation and secondary hemostasis. (A) Fibrinogen or in high shear environments vWF bridges platelets through activated GPIIb/IIla, leading to formation of an unstable platelet plug. Leukocytes are recruited to aggregated platelets via CD40/CD40L and PSGL1/CD62P interactions. Increased amounts of thrombin are generated on the platelet plug, which converts bound fibrinogen to fibrin, leading to plug stabilization and clot retraction. Microparticles as well as adhesion molecules (sCD62P, sCD40L) are shed from the platelet surface into the circulation as stimuli for leukocytes, T cells, and endothelial cells. (B) Scanning electron microscope preparation of a nonretracted platelet plug, induced by collagen. (C) REM-preparation of a platelet-fibrin clot with recruited red cell(s). vWF, von Willebrand factor; TSP, thrombospondin.

bind soluble ligands like plasma fibrinogen, vWF, TSP, fibronectin, or vitronectin. Only stimulation of a platelet leads to an increase in GPIIb/IIIa molecules, via $\alpha$-granule exocytosis, and to activation of surfaceexposed GPIIb/IIIa, enabling binding of soluble ligands. On the other hand, immobilized fibrinogen on stimulated platelets serves as an adhesive substrate for resting platelets through GPIIb/IIIa that leads to amplification of primary aggregation. ${ }^{23}$ Interaction between GPIIb/IIIa and its ligand is associated with molecular conformational changes, resulting in a firm connection. Activation-dependent changes in the conformation of GPIIb/IIIa can be detected biophysically or by specific antibodies. Ligand binding to GPIIb/IIIa induces additional conformational changes which lead to phosphor- ylation of tyrosines of the cytoplasmatic GPIIIachain. ${ }^{24,25}$ Disulfide changes in the GPIIb/IIIa complex by the surface-associated protein disulfide isomerase induce high affinity binding sites for fibrinogen. ${ }^{26}$ Fibrinogen links discoid platelets during the initial platelet-platelet contact. ${ }^{27}$ In high shear environments, as found in arterioles and stenosed arteries, platelet activation/aggregation can be induced by shear itself. In this case, platelets are first linked by $\mathrm{vWF}$ bridges via the GPIb/V/IX complex. This interaction leads to activation of GPIIb/IIIa (inside-out signaling) and in turn to stable vWF-mediated platelet aggregates. ${ }^{28}$

Low-density lipoproteins (LDL) are supposed to be also a ligand of GPIIb/IIIa and a modulator of 
platelet function. Increased levels of LDL are found in the plasma from patients who discontinued statin treatment and these elevated LDL levels are associated with platelet hyperactivity. The possible link between LDL and a corresponding prothrombotic state may explain the increased cardiovascular event rate after statin discontinuation. ${ }^{29}$ In addition, platelets recruit leukocytes and $\mathrm{T}$-cells into the growing plug. Interactions via $\mathrm{P}-$ selectin/PSGL1 or CD40L/CD40 mediate activation of leukocytes which trigger or limit thrombus growth. ${ }^{30}$ Circulating platelet-monocyte aggregates are supposed to play a role in enhancing formation of atherosclerotic plaques as well as in graft occlusion after peripheral vascular surgery. ${ }^{31,32}$ Formation of platelet-leukocyte associates via GPIb on platelets and Mac-1 on leukocytes may be a cause of the phenomenon of rapid clearance of transferred cooled platelets with activated clustered GPIb/V/IX complexes. ${ }^{33}$

\section{PROCOAGULANT ACTIVITY - MODEL OF RECEPTOR-MEDIATED THROMBIN GENERATION ON PLATELETS}

The formation of a stable platelet plug during secondary hemostasis is characterized by thrombin-mediated conversion of fibrinogen to fibrin. Thrombin is generated on surfaces of blood and vascular cells. However, the platelet membrane contains a specific lipid assembly and receptors with high-affinity binding sites for clotting factors, a favored preferential and specialized locus to induce and modulate secondary hemostatic processes. ${ }^{34,35}$

The plasma membrane of platelets consists predominantly of phospholipids ( 70\%), cholesterol, and glycolipids. The major phospholipids are phosphatidylcholine (PC), sphingomyelin (SphM), phosphatidylethanolamine (PE), phosphatidylserine (PS) and phosphatidylinositol (PI). They are localized asymmetrically in the plasma membrane, with a concentration of SphM and PC in the outer leaflet and of PE and acetylated arachidonic acid in the inner leaflet. Enzymes are distributed in a specific manner in different platelet membranes. It is postulated that only the plasma membrane contains adenylate cyclase. In contrast, enzymes responsible for thromboxane A2-synthesis, such as phospholipase A2, diglycerol lipase, cyclooxygenase (CO), and thromboxane synthase, are restricted to the intracellular dense tubular membranes. ${ }^{36}$ Platelet activation is associated with a flip-flop move of anionic phospholipids, for example, PS, from the inner to the outer leaflet, leading to an increase of PS from 2 to $12 \%$ of the phospholipid content. The exposure of anionic phospholipids on the platelet surface can be monitored by labeling of platelets with annexin $\mathrm{V}$, a specific ligand for amino phospholipids. ${ }^{37}$ The exposure of PS on aggregated platelets provides a catalytic surface for procoagu- lant processes, enabling thrombin generation at the site of injury. ${ }^{38} \mathrm{~A}$ recently identified alternatively spliced form of human tissue factor (TF) exhibits procoagulant activity when exposed as soluble molecule to phospholipids, suggesting that soluble TF contributes to thrombus growth. ${ }^{39}$

In contrast to the classic view of secondary hemostasis, a model of controlled thrombin generation on the platelet surface may explain many unresolved questions regarding hemophilia or the molecular mechanism of FVIIa in the clotting process. Small amounts of thrombin are formed on the surface of a TF presenting cell (fibroblast or activated monocyte or activated endothelial cell, respectively). These amounts of thrombin are not able to produce a stable fibrin clot, but are enough to activate platelets. Activated platelets can then bind coagulation factors and cofactors via $\mathrm{Ca}^{2+}$ and by specific receptors. ${ }^{40,41}$ Platelet-bound cofactors FV and FVIII are protected against cleavage by activated protein

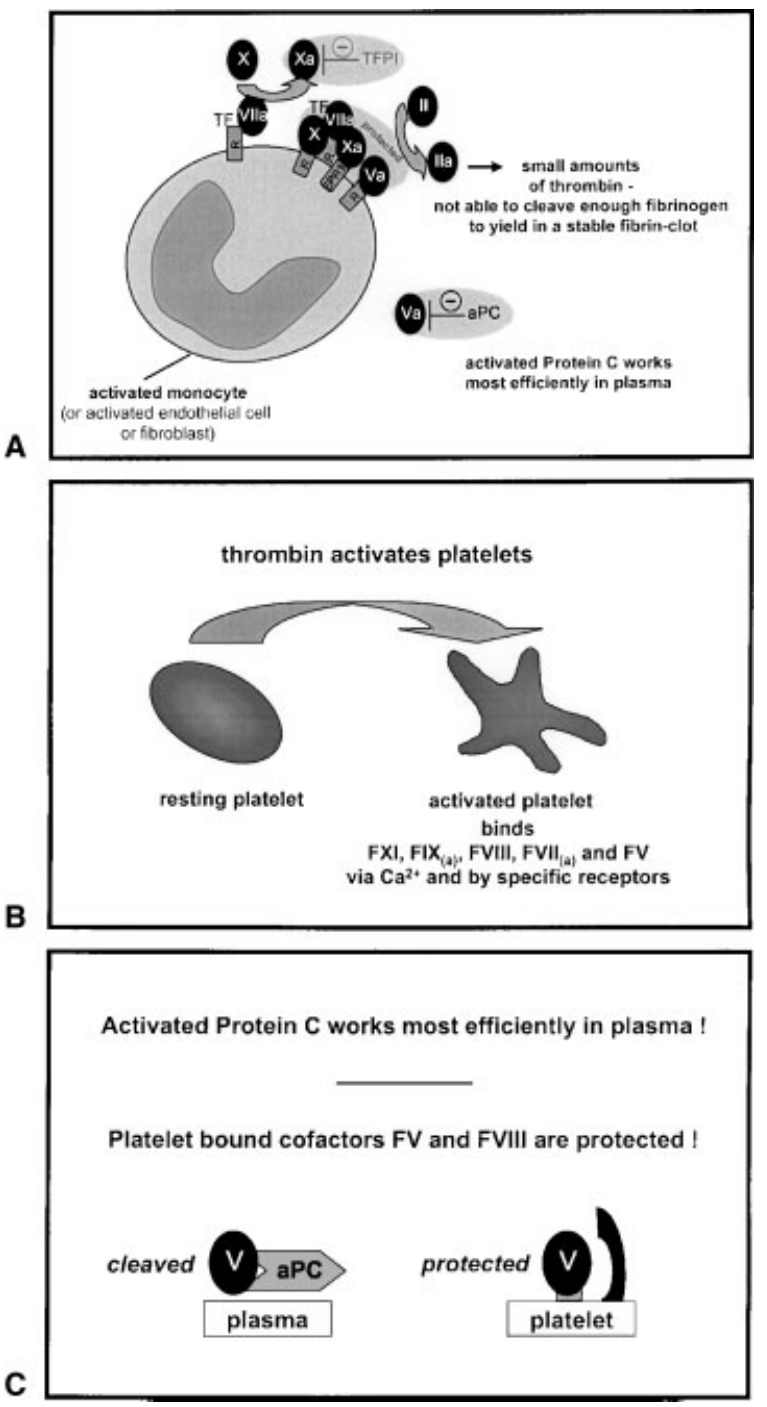


C. ${ }^{42}$ On the surface of the platelet, FXIa binds to its receptor GPIb and activates FIX. In contrast to FXa, which is readily inhibited by TF pathway inhibitor (TFPI) as soon as it enters the plasma, FIXa, built on
TF/FVIIa presenting cells can in addition diffuse to the activated platelets. On the platelet surface, the Xase complex and the prothrombinase complex have optimal conditions. ${ }^{43,44}$ The concerted actions of coagulation
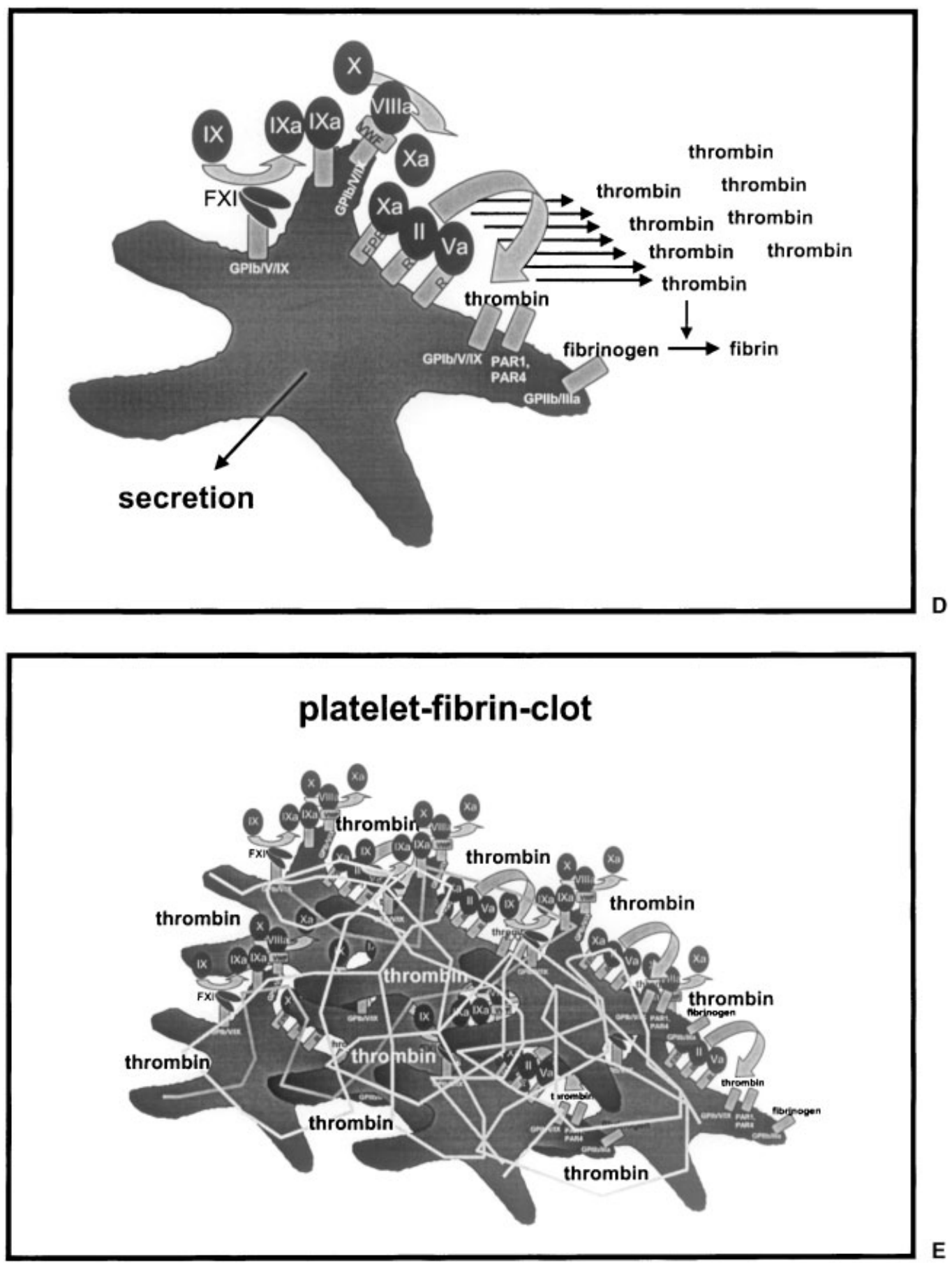

Figure 4 Model of receptor-mediated thrombin generation. (A) Small amounts of thrombin formed on the surface of a tissue factor (TF) presenting cell (fibroblast or activated monocyte or activated endothelial cell, respectively). These amounts of thrombin are not able to produce a stable fibrin clot, but are enough to activate platelets. (B) Activated platelets can then bind coagulation factors and cofactors via $\mathrm{Ca}^{2+}$ and by specific receptors. (C) Platelet-bound cofactors FV and FVIII are protected against cleavage by activated protein C. (D) On the surface of the platelet FXla binds to its receptor GPIb and activates FIX. In contrast to FXa that is readily inhibited by tissue factor pathway inhibitor (TFPI) as soon as it enters the plasma, FIXa, built on TF/FVIla presenting cells can in addition diffuse to the activated platelets. On the platelet surface the Xase-complex and the prothrombinase-complex have optimal conditions. (E) The concerted actions of coagulation factors on the platelet surface lead to a burst of thrombin formation, so that a stable fibrin clot can be formed. aPC, activated protein C; R, receptor; EPR1, effector cell protease receptor 1, PAR, protease activated receptor. 
factors yield on the platelet surface in a burst of thrombin formation, so that a stable fibrin clot can be formed (Fig. 4). ${ }^{45,46}$

\section{MICROVESICLE RELEASE/SHEDDING OF ADHESION MOLECULES}

Strong agonists like collagen in combination with thrombin or complement (C5b-9) induce shedding of microvesicles from the platelet surface. This "budding" process is due to $\mathrm{Ca}^{2+}$-mediated activation of calpain and leads to vesicles containing exclusively intracytoplasmatic substances. ${ }^{47,48}$ These vesicles are procoagulant and show similar surface expression of activationdependent adhesion molecules (P-selectin, CD40L) as stimulated platelets. Platelet-derived microparticles are found to be increased in the circulation of patients with sepsis or after cardiopulmonary bypass and are thought to be associated with thrombotic diseases. ${ }^{49}$ Therefore, defects in shedding of platelet-microvesicles is associated with bleeding disorders. It has been shown that plateletmicrovesicles bind to and activate leukocytes and endothelial cells, bridging leukocytes to each other or leukocytes with endothelial cells via PSGL1 L-selectin, P-selectin/PSGL1, and CD40L/CD40, respectively. ${ }^{50}$ Upon platelet stimulation, surface-expressed CD62P as well as CD40L are further cleaved in soluble fragments. ${ }^{51,52}$ sCD62P is known to induce a procoagulant state of monocytes. Platelet-derived sCD40L is sup- posed to be a potent stimulus for $\mathrm{T}$-cells, endothelial cells, and platelets and seems to be necessary for stability of arterial thrombi (Fig. 3)..$^{53-55}$

\section{SIGNAL TRANSDUCTION - STIMULATORY SIGNALING}

Stimulatory platelet signaling as a result of receptor ligation and receptor cross-linking leads to production and release of several intracellular messenger molecules: $\mathrm{Ca}^{2+}$, products of the phospholipase C (PLC)-mediated phosphoinositol hydrolysis, diacylgycerol, inosit-1,4,5triphosphat (IP3), and thromboxane $\mathrm{A}_{2}\left(\mathrm{TxA}_{2}\right)$. Platelet agonists like $\mathrm{ADP}, \mathrm{TxA}_{2}$, epinephrine, serotonin, and thrombin interact with seven specific transmembrane receptors that are coupled by GTP-binding heterotrimeric $G$-proteins, initiating several signaling pathways (Fig. 5). Signaling through receptors coupled to the Gqfamily of G-proteins (PAR1, PAR4, TxA 2 -receptor, 5-HT2A-receptor) leads to activation of PLC. PLC catalyzes the hydrolysis of phosphatidyl inositolbisphosphate (PIP2) to IP3, which induces the mobilization of $\mathrm{Ca}^{2+}$ from the dense tubula system. An increase in intracellular $\mathrm{Ca}^{2+}$ is associated with a phosphorylation of the myosin-light-chain by myosin-light-chain kinase, a process that is necessary for shape change. In addition, receptor signaling through Ga12/13-proteins (PAR1, PAR4), contributes to shape change, too. ${ }^{56}$ Granule secretion is one relevant process in response to $\mathrm{Ca}^{2+}$

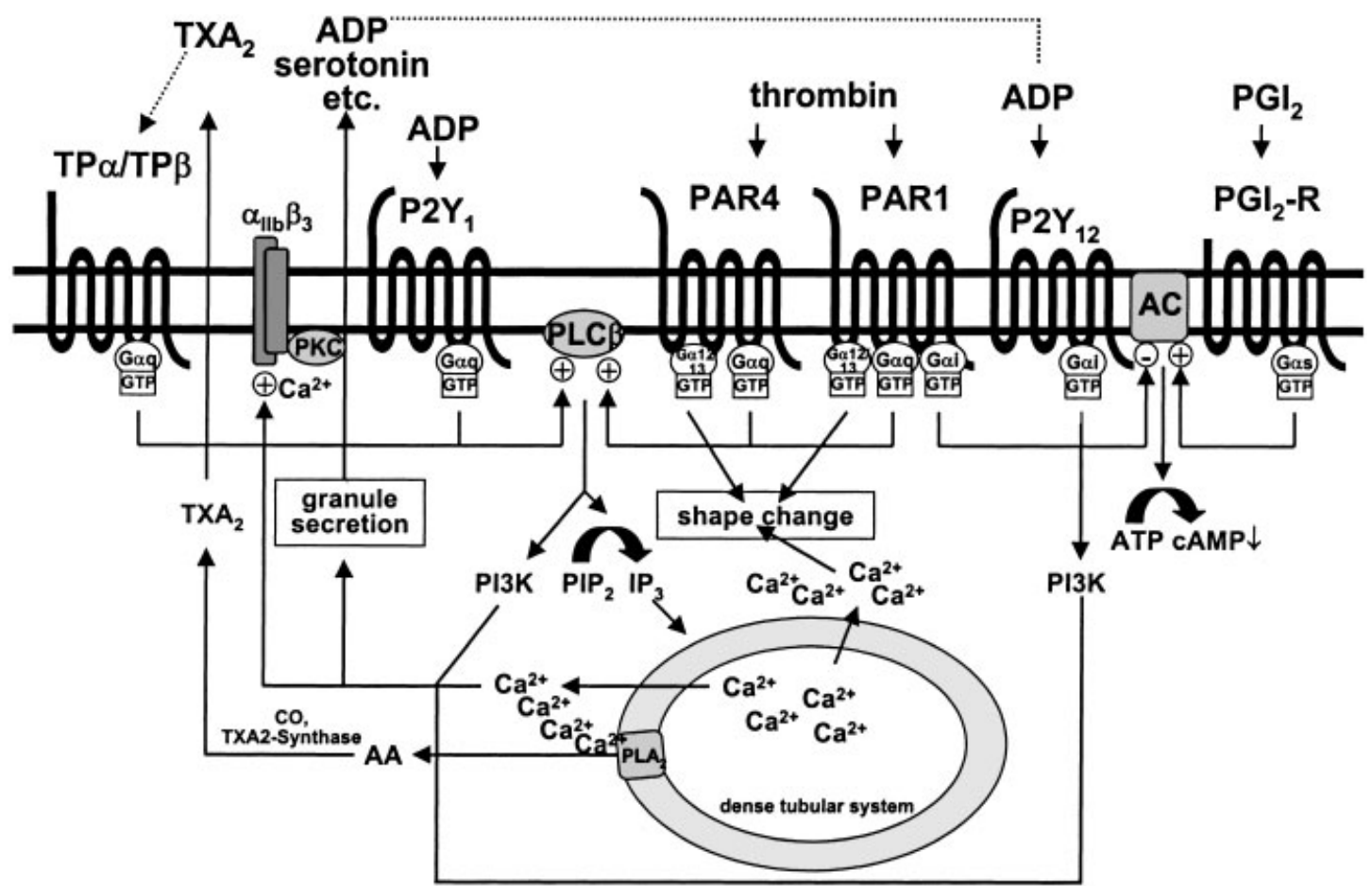

Figure 5 G-protein coupled seven-transmembrane receptor signaling in platelets. GTP, guanidine triphosphate; PKC, protein kinase C; $\mathrm{TXA}_{2}$, thromboxane $\mathrm{A}_{2}, \mathrm{CO}$, cyclooxygenase; PI3K, phosphatidylinositol-3 kinase; PIP2, phosphatidylinositolbiphosphate; IP3, inosit1,4,5-triphosphate; PLA, phospholipase A; AC, adenylatecyclase; cAMP, cyclic adenosine monophosphate; ADP, adenosine diphosphate; ATP, adenosine triphosphate; $\mathrm{PGI}_{2}$, prostaglandin $I_{2}, R$, receptor; PAR, protease activated receptor. 
mobilization, which leads to release of ADP from the dense bodies. ADP binds back to $\mathrm{P}_{2} \mathrm{Y}_{12}$ and amplifies platelet activation. ${ }^{57}$ Another activation-enhancing pathway is characterized by the synthesis and release of $\mathrm{TxA}_{2}$ which results from $\mathrm{Ca}^{2+}$-dependent mobilization of arachidonic acid by phospholipase $\mathrm{A} 2$ and subsequent metabolism through the $\mathrm{CO}$ and $\mathrm{TxA}_{2}$-synthase. Secreted $\mathrm{TxA}_{2}$ in turn rebinds to its Gq-coupled TPreceptors and potentiates stimulatory processes. ${ }^{58}$ This pathway is not essential for GPIIb/IIIa activation, secretion, and aggregation. ${ }^{59}$ Therefore, blocking this pathway by acetylsalicylic acid (COX-inhibitor), $\mathrm{TxA}_{2}$ receptor inhibitors, or $\mathrm{TxA}_{2}$-synthase inhibitors does not inhibit platelet activation completely. Secreted ADP activates additional $\mathrm{Gi}$-mediated pathways via its $\mathrm{P} 2 \mathrm{Y}_{12}$-receptor, leading to inhibition of adenylcyclase with subsequent decrease of the activation blocking messenger cAMP. Pepducins, cell-penetrating peptides, are novel intracellular inhibitors of signal transduction from receptor to G-proteins. ${ }^{60}$ It has been shown that epinephrine signaling through $\mathrm{Gq}$-coupled $\alpha 2$ a receptor stimulation shares the final part of the $\mathrm{P} 2 \mathrm{Y}_{12}$-receptor signaling pathway. ${ }^{61}$ This "bypass effect" of epinephrine may possibly explain why thienopyridine drugs (ticlopidine, clopidogrel), affecting the $\mathrm{P}_{2} \mathrm{Y}_{12}$-receptor, are not as successful in antithrombotic therapy of ischemic arterial vascular diseases as hoped.

Signaling via collagen, immunoglobulins and vWF depends on nonreceptor tyrosine kinases. Platelet stimulation in response to collagen involves signaling by the major collagen receptors GPIa/IIa and GPVI
(Fig. 6). The signaling via GPVI, which is associated with an Fc-receptor $\gamma$ chain, is similar to antigenreceptor-mediated signaling in $\mathrm{T}$ and $\mathrm{B}$ cells. ${ }^{62,63}$ Cross-linking of GPVI/FcR $\gamma$ chain by collagen ligation leads to phosphorylation of the immunoreceptor tyrosine-based activation motif (ITAM) of the $\mathrm{FcR} \gamma$ chain by the Src-tyrosine kinases Lyn and Fyn with subsequent binding and activation of the nonreceptor tyrosine kinase Syk. The participation of Syk and the adapters LAT and SLP76 leads to activation of phospholipase $\mathrm{C} \gamma 2$ (PLC $\gamma 2)$. The formation of lipid rafts may be essential for the integration of the key signaling complexes, leading to PLC $\gamma 2$ activation. ${ }^{64}$ Activation of PLC $\gamma 2$ results in IP3-synthesis, and the subsequent downstream pathways are similar to those induced by $\mathrm{Gq}$-coupled receptors. As a consequence GPIIb/IIIa receptors are activated, enabling binding of soluble ligands, which in turn leads to activation of Syk (outside-in signaling), contributing to actin polymerization and platelet spreading. ${ }^{65}$ Recently it has been revealed that GPIa/IIa may couple to many of the same intracellular signaling molecules as GPVI. ${ }^{66,67}$ Therefore, the roles of GPVI and $\mathrm{GPI} / \mathrm{II} a$ are not as easy to distinguish as originally thought.

\section{SIGNAL TRANSDUCTION - INHIBITORY SIGNALING}

For regulation and limitation of collagen-induced thrombus formation, platelets express platelet-endothelial cell adhesion molecule-1 (CD31), a member of

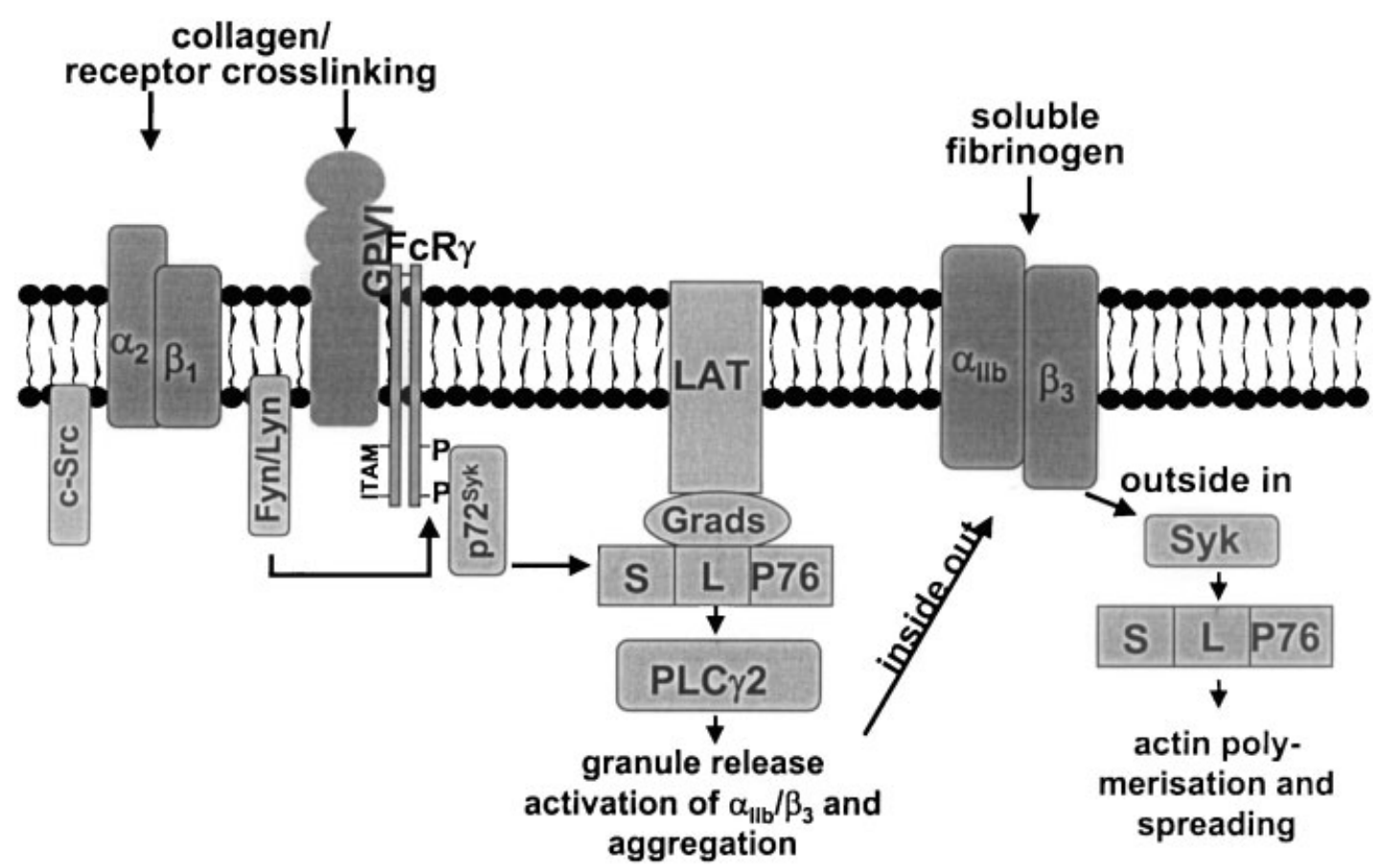

Figure 6 Nonreceptor tyrosine kinase mediated collagen signaling in platelets. Tyrosine-kinases: c-Src, Fyn/Lyn; non receptor tyrosine kinases; p72 ${ }^{\text {Syk }}$, Syk, adapter molecules: LAT, Grads, SLP76; PLC: phospholipase C; ITAM: immunoreceptor tyrosine based activation motif. 
the inhibitory receptor family. Cross-linking of CD31 includes phosphorylation of immunoreceptor tyrosinebased inhibition motifs (ITIMS), inhibiting the actions of ITAMS. ${ }^{68,69}$

In the absence of a wound, platelet activation is counteracted by signaling from prostaglandin $\mathrm{I}_{2}\left(\mathrm{PGI}_{2}\right)$ and EDRF/nitric oxide (NO), released from endothelial cells. Both platelet inhibitors induce an intracellular increase of the second messenger cAMP/cGMP by activation of adenylate cyclase $\left(\mathrm{PGI}_{2}\right)$ and guanylate cyclase (NO), respectively. ${ }^{70}$ High concentrations of cyclic mononucleotides lead to a decrease in IP3 synthesis and $\mathrm{Ca}^{2+}$ mobilization, resulting in reduction of platelet activation. ${ }^{71,72}$

These fascinating little cells called platelets are much more important in hemostasis than originally thought. We are looking forward to a future that will unravel platelets' role in other physiologic and pathologic processes such as inflammation, sepsis, asthma, ischemia reperfusion injury, and host defense.

\section{REFERENCES}

1. Bhatt DL, Topol EJ. Scientific and therapeutic advances in antiplatelet therapy. Nat Rev Drug Discov 2003;2:15-28

2. Shattil SJ, Ginsberg MH, Brugge JS. Adhesive signaling in platelets. Curr Opin Cell Biol 1994;6:695-704

3. Fox JE. The platelet cytoskeleton. Thromb Haemost 1993; 70:884-893

4. Clemetson KJ, Clemetson JM. Platelet GPIb-V-IX complex. Structure, function, physiology, and pathology. Semin Thromb Hemost 1995;21:130-136

5. Jurk K, Clemetson KJ, de Groot PG, et al. Thrombospondin1 mediates platelet adhesion at high shear via glycoprotein $\mathrm{Ib}$ (GPIb): an alternative/backup mechanism to von Willebrand factor. FASEB J 2003;17:1490-1492

6. Frenette PS, Denis CV, Weiss L, et al. P-Selectin glycoprotein ligand 1 (PSGL-1) is expressed on platelets and can mediate platelet-endothelial interactions in vivo. J Exp Med 2000;191:1413-1422

7. Romo GM, Dong JF, Schade AJ, et al. The glycoprotein IbIX-V complex is a platelet counterreceptor for P-selectin. J Exp Med 1999;190:803-814

8. Kehrel B. Platelet-collagen interactions. Semin Thromb Hemost 1995;21:123-129

9. Kehrel B, Balleisen L, Kokott R, et al. Deficiency of intact thrombospondin and membrane glycoprotein Ia in platelets with defective collagen-induced aggregation and spontaneous loss of disorder. Blood 1988;71:1074-1078

10. Polgar J, Clemetson JM, Kehrel BE, et al. Platelet activation and signal transduction by convulxin, a C-type lectin from Crotalus durissus terrificus (tropical rattlesnake) venom via the p62/GPVI collagen receptor. J Biol Chem 1997;272: 13576-13583

11. Kehrel BE, Wierwille S, Clemetson KJ, et al. Glycoprotein VI is a major collagen receptor for platelet activation: it recognizes the platelet-activating quaternary structure of collagen, whereas CD36, glycoprotein IIb/IIIa, and von Willebrand factor do not. Blood 1998;91:491-499
12. Clemetson JM, Polgar J, Magnenat E, Wells TN, Clemetson $\mathrm{KJ}$. The platelet collagen receptor glycoprotein VI is a member of the immunoglobulin superfamily closely related to FcalphaR and the natural killer receptors. J Biol Chem 1999;274:29019-29024

13. Rendu F, Brohard-Bohn B. The platelet release reaction: granules' constituents, secretion and functions. Platelets 2001; 12:261-273

14. Gachet C. ADP receptors of platelets and their inhibition. Thromb Haemost 2001;86:222-232

15. Fabre JE, Nguyen M, Latour A, et al. Decreased platelet aggregation, increased bleeding time and resistance to thromboembolism in P2Y1-deficient mice. Nat Med 1999; 5:1199-1202

16. Dorsam RT, Kunapuli SP. Central role of the P2Y(12) receptor in platelet activation. J Clin Invest 2004;113:340-345

17. Marcus AJ, Broekman MJ, Drosopoulos JH, et al. The endothelial cell ecto-ADPase responsible for inhibition of platelet function is CD39. J Clin Invest 1997;99:13511360

18. Dale GL, Friese P, Batar P, et al. Stimulated platelets use serotonin to enhance their retention of procoagulant proteins on the cell surface. Nature 2002;415:175-179

19. Nesbitt WS, Giuliano S, Kulkarni S, Dopheide SM, Harper IS, Jackson SP. Intercellular calcium communication regulates platelet aggregation and thrombus growth. J Cell Biol 2003; 160:1151-1161

20. Kehrel B, Flicker E, Wigbels B, Osterfeld M, van de Loo J, Luscher EF. Thrombospondin measured in whole blood-an indicator of platelet activation. Blood Coagul Fibrinolysis 1996;7:202-205

21. Singbartl K, Forlow SB, Ley K. Platelet, but not endothelial, $\mathrm{P}$-selectin is critical for neutrophil-mediated acute postischemic renal failure. FASEB J 2001;15:2337-2344

22. Furie B, Furie BC, Flaumenhaft R. A journey with platelet Pselectin: the molecular basis of granule secretion, signalling and cell adhesion. Thromb Haemost 2001;86:214-221

23. Lüscher EF, Weber A. The formation of the haemostatic plug-a special case of platelet aggregation. An experiment and a survey of the literature. Thromb Haemost 1993;70:234237

24. Phillips DR, Law D, Scarborough RM. Glycoprotein IIb-IIIa in platelet aggregation: an emerging target for the prevention of acute coronary thrombotic occlusions. Arch Pathol Lab Med 1998;122:811-812

25. Payrastre B, Missy K, Trumel C, Bodin S, Plantavid M, Chap H. The integrin alpha IIb/beta 3 in human platelet signal transduction. Biochem Pharmacol 2000;60:10691074

26. Lahav J, Jurk K, Hess O, et al. Sustained integrin ligation involves extracellular free sulfhydryls and enzymatically catalyzed disulfide exchange. Blood 2002;100:2472-2478

27. Morgenstern E, Kehrel BE, Matzdorff A, et al. How do platelets aggregate? [abstract]Ann Hematol 2001;80:48

28. Ruggeri ZM. Mechanisms of shear-induced platelet adhesion and aggregation. Thromb Haemost 1993;70:119-123

29. Puccetti L, Pasqui AL, Pastorelli M, et al. Platelet hyperactivity after statin treatment discontinuation. Thromb Haemost 2003;90:476-482

30. Falati S, Liu Q, Gross P, et al. Accumulation of tissue factor into developing thrombi in vivo is dependent upon microparticle P-selectin glycoprotein ligand 1 and platelet P-selectin. J Exp Med 2003;197:1585-1598 
31. Huo Y, Schober A, Forlow SB, et al. Circulating activated platelets exacerbate atherosclerosis in mice deficient in apolipoprotein E. Nat Med 2003;9:61-67

32. Esposito CJ, Popescu WM, Rinder HM, et al. Increased leukocyte-platelet adhesion in patients with graft occlusion after peripheral vascular surgery. Thromb Haemost 2003;90: 1128-1134

33. Hoffmeister KM, Josefsson EC, Isaac NA, Clausen H, Hartwig JH, Stossel TP. Glycosylation restores survival of chilled blood platelets. Science 2003;301:1531-1534

34. Bouchard BA, Catcher CS, Thrash BR, Adida C, Tracy PB. Effector cell protease receptor-1, a platelet activationdependent membrane protein, regulates prothrombinasecatalyzed thrombin generation. J Biol Chem 1997;272: 9244-9251

35. Monroe DM, Hoffman M, Roberts HR. Platelets and thrombin generation. Arterioscler Thromb Vasc Biol 2002; 22:1381-1389

36. Zwaal RF, Schroit AJ. Pathophysiologic implications of membrane phospholipid asymmetry in blood cells. Blood 1997;89:1121-1132

37. Dörmann D, Kardoeus J, Zimmermann RE, et al. Flowcytometric analysis of agonist-induced annexin $\mathrm{V}$, factor $\mathrm{Va}$ and factor Xa binding to human platelets. Platelets 1998;7:171177

38. Sims PJ, Wiedmer T, Esmon CT, Weiss HJ, Shattil SJ. Assembly of the platelet prothrombinase complex is linked to vesiculation of the platelet plasma membrane. Studies in Scott syndrome: an isolated defect in platelet procoagulant activity. J Biol Chem 1989;264:17049-17057

39. Bogdanov VY, Balasubramanian V, Hathcock J, Vele O, Lieb M, Nemerson Y. Alternatively spliced human tissue factor: a circulating, soluble, thrombogenic protein. Nat Med 2003;9: 458-462

40. Nesheim ME, Furmaniak-Kazmierczak E, Henin C, Cote G. On the existence of platelet receptors for factor $\mathrm{V}(\mathrm{a})$ and factor VIII(a). Thromb Haemost 1993;70:80-86

41. Bouchard BA, Tracy PB. Platelets, leukocytes, and coagulation. Curr Opin Hematol 2001;8:263-269

42. Oliver JA, Monroe DM, Roberts HR, Hoffman M. Thrombin activates factor XI on activated platelets in the absence of factor XII. Arterioscler Thromb Vasc Biol 1999; 19:170-177

43. Monroe DM, Hoffman M, Oliver JA, Roberts HR. Platelet activity of high-dose factor VIIa is independent of tissue factor. Br J Haematol 1997;99:542-547

44. Scandura JM, Walsh PN. Factor X bound to the surface of activated human platelets is preferentially activated by platelet-bound factor IXa. Biochemistry 1996;35:8903-8913

45. Dormann D, Clemetson KJ, Kehrel BE. The GPIb thrombin-binding site is essential for thrombin-induced platelet procoagulant activity. Blood 2000;96:2469-2478

46. Brass LF. More pieces of the platelet activation puzzle slide into place. J Clin Invest 1999;104:1663-1665

47. Holme PA, Orvim U, Hamers MJ, et al. Shear-induced platelet activation and platelet microparticle formation at blood flow conditions as in arteries with a severe stenosis. Arterioscler Thromb Vasc Biol 1997;17:646-653

48. Wiedmer T, Shattil SJ, Cunningham M, Sims PJ. Role of calcium and calpain in complement-induced vesiculation of the platelet plasma membrane and in the exposure of the platelet factor Va receptor. Biochemistry 1990;29:623632
49. Nieuwland R, Berckmans RJ, Rotteveel-Eijkman RC, et al. Cell-derived microparticles generated in patients during cardiopulmonary bypass are highly procoagulant. Circulation 1997;96:3534-3541

50. Henn V, Slupsky JR, Grafe M, et al. CD40 ligand on activated platelets triggers an inflammatory reaction of endothelial cells. Nature 1998;391:591-594

51. Hartwell DW, Mayadas TN, Berger G, et al. Role of Pselectin cytoplasmic domain in granular targeting in vivo and in early inflammatory responses. J Cell Biol 1998;143:11291141

52. Henn V, Steinbach S, Buchner K, Presek P, Kroczek RA. The inflammatory action of CD40 ligand (CD154) expressed on activated human platelets is temporally limited by coexpressed CD40. Blood 2001;98:1047-1054

53. Aukrust P, Muller F, Ueland T, et al. Enhanced levels of soluble and membrane-bound CD40 ligand in patients with unstable angina. Possible reflection of $\mathrm{T}$ lymphocyte and platelet involvement in the pathogenesis of acute coronary syndromes. Circulation 1999;100:614-620

54. Hollenbaugh D, Mischel-Petty N, Edwards CP, et al. Expression of functional CD40 by vascular endothelial cells. J Exp Med 1995;182:33-40

55. Andre P, Prasad KS, Denis CV, et al. CD40L stabilizes arterial thrombi by a beta3 integrin-dependent mechanism. Nat Med 2002;8:247-252

56. Brass LF. Thrombin and platelet activation. Chest 2003; 124:18S-25S

57. Hollopeter G, Jantzen HM, Vincent D, et al. Identification of the platelet ADP receptor targeted by antithrombotic drugs. Nature 2001;409:202-207

58. Rao AK. Congenital disorders of platelet function: disorders of signal transduction and secretion. Am J Med Sci 1998; 316:69-76

59. Rinder CS, Student LA, Bonan JL, Rinder HM, Smith BR. Aspirin does not inhibit adenosine diphosphate-induced platelet alpha-granule release. Blood 1993;82:505-512

60. Covic L, Misra M, Badar J, Singh C, Kuliopulos A. Pepducin-based intervention of thrombin-receptor signaling and systemic platelet activation. Nat Med 2002;8:1161-1165

61. Yang J, Wu J, Kowalska MA, et al. Loss of signaling through the $\mathrm{G}$ protein, $\mathrm{Gz}$, results in abnormal platelet activation and altered responses to psychoactive drugs. Proc Natl Acad Sci USA 2000;97:9984-9989

62. Clemetson KJ. Platelet activation: signal transduction via membrane receptors. Thromb Haemost 1995;74:111-116

63. Clemetson KJ, Clemetson JM. Platelet collagen receptors. Thromb Haemost 2001;86:189-197

64. Bodin S, Viala C, Ragab A, Payrastre B. A critical role of lipid rafts in the organization of a key FcgammaRIIa-mediated signaling pathway in human platelets. Thromb Haemost 2003;89:318-330

65. Gao J, Zoller KE, Ginsberg MH, Brugge JS, Shattil SJ. Regulation of the pp72syk protein tyrosine kinase by platelet integrin alpha IIb beta 3. EMBO J 1997;16:6414-6425

66. Inoue O, Suzuki-Inoue K, Dean WL, Frampton J, Watson SP. Integrin alpha2beta1 mediates outside-in regulation of platelet spreading on collagen through activation of $\mathrm{Src}$ kinases and PLCgamma2. J Cell Biol 2003;160:769-780

67. Woodside DG, Obergfell A, Leng L, et al. Activation of Syk protein tyrosine kinase through interaction with integrin beta cytoplasmic domains. Curr Biol 2001;11:17991804 
68. Newman PJ. Switched at birth: a new family for PECAM-1. J Clin Invest 1999;103:5-9

69. Newton-Nash DK, Newman PJ. A new role for plateletendothelial cell adhesion molecule-1 (CD31): inhibition of TCR-mediated signal transduction. J Immunol 1999;163: 682-688

70. Geiger J. Inhibitors of platelet signal transduction as antiaggregatory drugs. Expert Opin Investig Drugs 2001;10:865890

71. Aszodi A, Pfeifer A, Ahmad M, et al. The vasodilatorstimulated phosphoprotein (VASP) is involved in cGMPand cAMP-mediated inhibition of agonist-induced platelet aggregation, but is dispensable for smooth muscle function. EMBO J 1999;18:37-48

72. Schwarz UR, Walter U, Eigenthaler M. Taming platelets with cyclic nucleotides. Biochem Pharmacol 2001;62:11531161

73. Beumer S, IJsseldijk MJ, de Groot PG, Sixma JJ. Platelet adhesion to fibronectin in flow: dependence on surface concentration and shear rate, role of platelet membrane glycoproteins GP IIb/IIIa and VLA-5, and inhibition by heparin. Blood 1994;84:3724-3733

74. Timpl R, Brown JC. The laminins. Matrix Biol 1994;14:275281

75. Fernandez-Patron C, Martinez-Cuesta MA, Salas E, et al. Differential regulation of platelet aggregation by matrix metalloproteinases-9 and -2. Thromb Haemost 1999;82: 1730-1735

76. Galt SW, Lindemann S, Allen L, et al. Outside-in signals delivered by matrix metalloproteinase-1 regulate platelet function. Circ Res 2002;90:1093-1099

77. Bornstein P. Cell-matrix interactions: the view from the outside. Methods Cell Biol 2002;69:7-11

78. Angelillo-Scherrer A, de Frutos P, Aparicio C, et al. Deficiency or inhibition of Gas6 causes platelet dysfunction and protects mice against thrombosis. Nat Med 2001;7:215221

79. Moers A, Nieswandt B, Massberg S, et al. G13 is an essential mediator of platelet activation in hemostasis and thrombosis. Nat Med 2003;9:1418-1422

80. Abi-Younes S, Si-Tahar M, Luster AD. The CC chemokines MDC and TARC induce platelet activation via CCR4. Thromb Res 2001;101:279-289

81. Clemetson KJ, Clemetson JM, Proudfoot AE, Power CA, Baggiolini M, Welb TN. Functional expression of CCR1, CCR3, CCR4, and CXCR4 chemokine receptors on human platelets. Blood 2000;96:4046-4054

82. Kowalska MA, Ratajczak MZ, Majka M, et al. Stromal cell-derived factor-1 and macrophage-derived chemokine: 2 chemokines that activate platelets. Blood 2000;96: $50-57$ 